\title{
GÜREŞÇILERDE REAKTIF KUVVET INDEKSI, MAKSIMAL KUVVET VE ANAEROBIK GÜÇ
}

\author{
Yazarlar \\ Doç. Dr. Mehmet ÖZAL \\ Sinan KARA
}




\title{
(C) Copyright 2021
}

Bu kitabın, basım, yayın ve satıș hakları Akademisyen Kitabevi A.Ş.'ne aittir. Anılan kuruluşun izni alınmadan kitabın tümü ya da bölümleri mekanik, elektronik, fotokopi, manyetik kağıt ve/veya başka yöntemlerle çoğaltılamaz, basılamaz, dağıtılamaz. Tablo, şekil ve grafikler izin alınmadan, ticari amaçh kullanılamaz. Bu kitap T.C. Kültür Bakanlığı bandrolü ile satılmaktadır.

\section{ISBN}

978-625-7409-40-7

\section{Kitap Adı}

Güreşçilerde Reaktif Kuvvet İndeksi, Maksimal Kuvvet ve Anaerobik Güç

\author{
Yazarlar \\ Mehmet ÖZAL \\ ORCİD iD: 0000-0002-9864-5178 \\ mozal@ybu.edu.tr \\ Sinan KARA \\ ORCID iD: 0000-0002-3091-6867 \\ sinankara@gazi.edu.tr \\ Yayın Koordinatörü \\ Yasin DİLMEN \\ Sayfa ve Kapak Tasarımı \\ Akademisyen Dizgi Ünitesi \\ Yayıncı Sertifika No \\ 47518 \\ Baskı ve Cilt \\ Vadi Matbaacllık \\ Bisac Code \\ SPO053000 \\ DOI \\ $\mathrm{X}$
}

\section{GENEL DAĞITIM}

\section{Akademisyen Kitabevi A.Ş.}

Halk Sokak 5 / A

Yenişehir / Ankara

Tel: o312 4311633

siparis@akademisyen.com 


\section{İÇINDEKİLER}

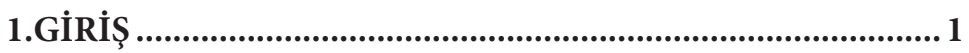

2.GENEL BİLGİLER........................................................... 7

2.1. Güreş ..................................................................................... 7

2.2. Türkiye’de Güreş Sporunun Tarihsel Gelişimi ............................. 8

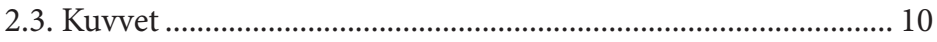

2.4. Kuvveti Etkileyen Unsurlar .......................................................... 11

2.4.1. Motor Birim Katılımı (Recruitment) ............................. 11

2.4.2. Motor Birim Ateşleme Hızı (Oranı)................................ 12

2.4.3. Gerilme-Kısalma Döngüsü ............................................ 12

2.4.4. Sinir-Kas Uyarımlarının Engellenmesi............................ 12

2.4.5. Kas Fibril Tipi..................................................................... 13

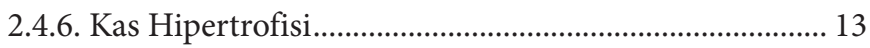

2.5. Kuvvet Biçimleri ............................................................................ 14

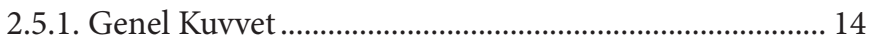

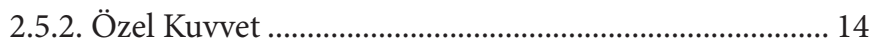

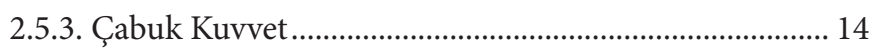

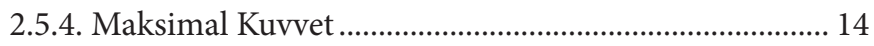

2.5.5. Kassal Dayanıklılık ......................................................... 16

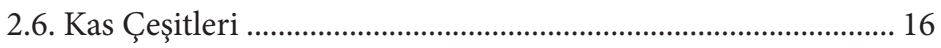

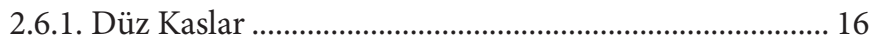

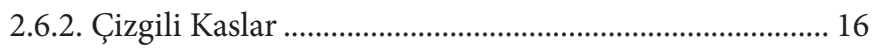

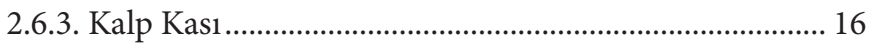

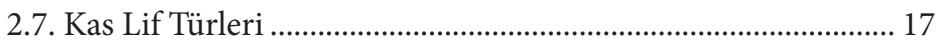

2.7.1. Tip I (Yavaş Kasılan) Lif Türü ........................................... 17

2.7.2. Tib II (Hızlı Kasılan) Lif Türü............................................ 18

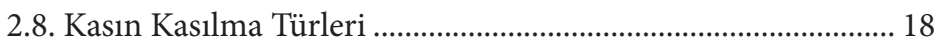

2.8.1. İzometrik Kas Kasılmas1 ................................................. 18

2.8.2. İzotonik Kas Kasılması................................................... 19 
2.8.3. Konsantrik Kas Kasılma..................................................... 19

2.8.4. Eksantrik Kas Kasılmas1 .................................................. 19

2.9. Enerji Sistemleri.......................................................................... 19

2.9.1. ATP-PC Fosfojen Sistem (Alaktik Anaerobik) ............. 20

2.9.2. Laktik Asit Sistemi (Anaerobik Glikoz)......................... 21

3. MATERYAL VE YÖNTEM ................................................ 23

3.1. Çalışma Grubunun Seçilmesi.................................................. 23

3.2. Deney Protokolü ........................................................................ 25

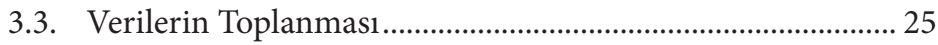

3.3.1. Boy Uzunluğu Ölçümü ...................................................... 25

3.3.2. Yağ Oranı ve Vücut Ağırlığı Ölçümleri .......................... 26

3.3.3. Reaktif Kuvvet İndeksi (RKİ) Ölçümü ............................ 27

3.3.4. Dikey Sıçrama ve Anaerobik Güç Ölçümleri................. 29

3.3.5. Bacak Kuvveti Ölçümü .................................................... 30

3.3.6. Kavrama Kuvveti Ölçümü ................................................ 31

3.4. İstatistiksel Analizler .................................................................. 32

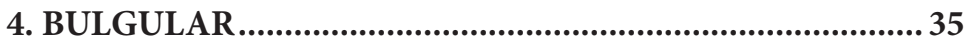

4.1. Sporcuların Stillerine Göre Yaş, Boy Uzunluğu ve Vücut Ağırlıklarının Karşılaştırılması ..................................................... 35

4.2. Sporcuların Stillerine Göre Vücut Kitle İndeksi, Vücut Yağ Yüzdesi ve Yağsız Vücut Ağırlığı Karşılaştırılması ................. 36

4.3. Grekoromen ve Serbest Stil Güreşçilerde RKİ, Maksimal Kuvvet ve Anaerobik Güç Özelliklerinin

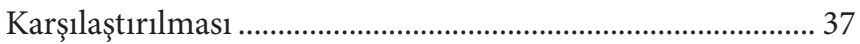

4.4. Grekoromen ve Serbest Stil Güreşçilerde Yere Temas Süresi, Sıçrama Yüksekliği ve Havada Kalma Süresi özelliklerinin

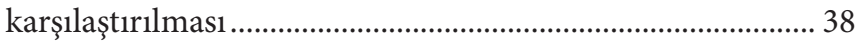

4.5. Grekoromen ve Serbest Stil Güreşçilerde Sağ ve Sol Kavrama Kuvvet Özelliklerinin Karşılaştırılması

4.6. Tüm Sporcular için Maksimal Kuvvet ile RKİ Arasındaki İlişkinin İncelenmesi ............................................................... 40

4.7. Tüm Sporcular için Maksimal Kuvvet ile Anaerobik Güç Arasındaki İlişkinin İncelenmesi. 
4.8. Tüm Sporcular için Maksimal Kuvvet ile Sıçrama Yüksekliği Arasındaki İlişkinin İncelenmesi

4.9. Tüm Sporcular için Maksimal Kuvvet ile Yere Temas Süresi Arasındaki İlișkinin İncelenmesi.

4.10. Tüm Sporcular için Maksimal Kuvvet ve Havada Kalma Süresi Arasındaki İlişkinin İncelenmesi

4.11. Tüm Sporcular için Maksimal Kuvvet ile Vücut Yağ Yüzdesi Arasındaki İlișkinin İncelenmesi.

4.12. Tüm Sporcular için Anaerobik Güç ile RKİ, Vücut Yağ Yüzdesi, Yere Temas Süresi, Sıçrama Yüksekliği ve Havada Kalma Süresi Arasındaki İlişkinin İncelenmesi 46

4.13. Grekoromen ve Serbest Stil Güreşçilerde Maksimal Kuvvet ile RKİ Arasındaki İlişkinin İncelenmesi

4.14. Grekoromen ve Serbest Stil Güreşçilerde Maksimal Kuvvet ile Anaerobik Güç Arasındaki İlişkinin İncelenmesi

4.15. Grekoromen ve Serbest Stil Güreşçilerde Maksimal Kuvvet ile Sıçrama Yüksekliği Arasındaki İlişkinin İncelenmesi

4.16. Grekoromen ve Serbest Stil Güreşçilerde Maksimal Kuvvet ile Yere Temas Süresi Arasındaki İlişkinin İncelenmesi ........ 5

4.17. Grekoromen ve Serbest Stil Güreşçilerde Maksimal Kuvvet ile Havada Kalma Süresi Arasındaki İlişkinin İncelenmesi

4.18. Grekoromen ve Serbest Stil Güreşçilerde Maksimal Kuvvet ile Vücut Yağ Yüzdesi Arasındaki İlişkinin İncelenmesi ...... 53

4.19. Grekoromen ve Serbest Stil Güreşçilerde Anaerobik Güç ile Vücut Yağ Yüzdesi, Sıçrama Yüksekliği, Havada Kalma Süresi, Yere Temas Süresi ve RKİ Arasındaki İlişkinin İncelenmesi

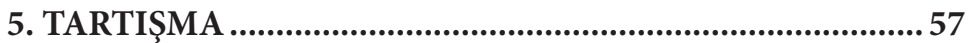

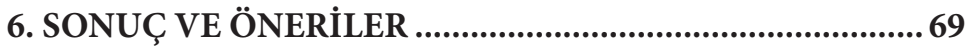

KAYNAKLAR ........................................................................... 71 



\title{
SIMMGELER VE KISALTMALAR DİZINNI
}

\author{
ADP: Adonezin difosfat \\ AG: Anaerobik güç \\ AP: Anaerobic power \\ ATP: Adenozin trifosfat \\ CM: Santimetre \\ KG: Kilogram \\ M: $\quad$ Metre \\ MK: Maksimal kuvvet \\ MS: Maximal strength \\ P: $\quad$ Fosfat \\ PC: $\quad$ Fosfo kreatin \\ RKİ: Reaktif kuvvet indeksi \\ RSI: Reaktive strength index \\ S: $\quad$ Saat \\ VA: Vücut ağırlığı \\ VKİ: Vücut kitle indeksi \\ VYY: Vücut yağ yüzdesi \\ Y: $\quad$ Yll \\ YVK: Yağsız vücut kütlesi
}





\section{KAYNAKLAR}

1. Bayraktar I. Farklı Spor Dallarında Pliometrik Güç Gelişiminin Anahtarı, 1. Baskı. 1992: 7-14.

2. Yaman M, Coşkuntürk OS. Sportif Performansın Sınırları, 1. Baskı. Ankara, 1992: 7-14.

3. Açak M, Açak M. Güreş Öğreniyorum, 1. Baskı. Malatya, Kubbealtı Yayıncilık, 2001: 1-6.

4. Cicioğlu İ, Kürkçü R, Eroğlu H, Yüksek S. 15-17 yaş grubu güreşçilerin fiziksel ve fizyolojik özelliklerinin sezonsal değişimi. Spormetre Beden Eğitimi Ve Spor Bilimleri Dergisi, 2007, 5(4): 151-156.

5. Chaabene H, Negra Y, Bouguezzi R, Mkaouer B, Franchini E, Julio U, Hachana Y. Physical and physiological attributes of wrestlers: an update. The Journal of Strength \& Conditioning Research, 2017, 31(5): 1411-1442.

6. Kılınç F, Özen G. Elit Serbest ve Grekoromen Güreşçilerin Anaerobik Güç Değerleri ve Kalp Atım Sayılarının Karşılaştırması. İnönü Üniversitesi Beden Eğitimi ve Spor Bilimleri Dergisi, 2015, 2(2): 21-34.

7. Kroshus E, Utter AC, Pierpoint LA, Currie DW, Knowles SB, Wasserman EB, Dompier TP, Marshall SW, Comstock RD, Kerr ZY. The first decade of web-based sports injury surveillance: descriptive epidemiology of injuries in US high school Boys' wrestling (2005-2006 through 2013-2014) and National Collegiate Athletic Association Men's wrestling (2004-2005 through 2013-2014). J Athl Train, 2018, 53(12): 1143-1155. 
8. Bayati R, Shamsi Majelan A, Mirzaei B, Barbas I. The effect of 12 weeks of wrestling+ warm-up program on functional movement screen scores in cadet wrestlers. Annals of Applied Sport Science, 2019, 7(1): 39-47.

9. Negaresh R, Del Coso J, Mokhtarzade M, Lima-Silva AE, Baker JS, Willems ME, Talebvand S, Khodadoost M, Farhani F. Effects of different dosages of caffeine administration on wrestling performance during a simulated tournament. Eur J Sport Sci, 2019, 19(4): 499-507.

10. Mirzaei B, Curby DG, Rahmani-Nia F, Moghadasi M. Physiological profile of elite Iranian junior freestyle wrestlers. The Journal of Strength \& Conditioning Research, 2009, 23(8): 2339-2344.

11. Gökdemir K. Güreş Antrenmanının Bilimsel Temelleri, 1. Baskı. Ankara, Poyraz Ofset, 2000: 71-74.

12. Cicioğlu İ. Pliometrik Antrenmanın 14-15 Yaş Grubu Basketbolcuların Dikey Sıçraması ile, Bazı Fiziksel ve Fizyolojik Parametreleri Üzerine Etkisi. Sağlık Bilimleri Enstitüsü, Beden Eğitimi ve Spor Anabilim Dalı. Ankara: Gazi Üniversitesi, 1995.

13. Suchomel TJ, Nimphius S, Stone MH. The importance of muscular strength in athletic performance. Sports Med, 2016, 46(10): 1419-1449.

14. Beattie K, Kenny IC, Lyons M, Carson BP. The effect of strength training on performance in endurance athletes. Sports Med, 2014, 44(6): 845-865.

15. Cormie P, McGuigan MR, Newton RU. Adaptations in athletic performance after ballistic power versus strength training. Medicine \& Science in Sports \& Exercise, 2010, 42(8): 1582-1598.

16. Seitz LB, Reyes A, Tran TT, de Villarreal ES, Haff GG. Increases in lower-body strength transfer positively to sprint performance: a systematic review with meta-analysis. Sports Med, 2014, 44(12): 1693-1702.

17. Beattie K, Carson BP, Lyons M, Kenny IC. The Relationship Between Maximal Strength and Reactive Strength. Int J Sport Physiol Perform, 2017, 12(4): 548-553.

18. Sáez de Villarreal E, Requena B, Cronin JB. The effects of plyometric training on sprint performance: A meta-analysis. The Journal of Strength \& Conditioning Research, 2012, 26(2): 575-584. 
19. Miller MG, Herniman JJ, Ricard MD, Cheatham CC, Michael TJ. The effects of a 6-week plyometric training program on agility. Journal of sports science \& medicine, 2006, 5(3): 459.

20. McCormick BT, Hannon JC, Newton M, Shultz B, Detling N, Young WB. The effects of frontal-and sagittal-plane plyometrics on change-of-direction speed and power in adolescent female basketball players. Int J Sport Physiol Perform, 2016, 11(1): 102-107.

21. Young W. Laboratory strength assessment of athletes. New studies in athletics, 1995, 10(1): 89-96.

22. Cormie P, McGuigan MR, Newton RU. Developing maximal neuromuscular power. Sports Med, 2011, 41(1): 17-38.

23. Young WB. Transfer of strength and power training to sports performance. Int J Sport Physiol Perform, 2006, 1(2): 74-83.

24. Jensen $\mathrm{R}$, editor Measurement techniques in assessing athletic power training. ISBS-Conference Proceedings Archive; 2009.

25. Flanagan EP, Ebben WP, Jensen RL. Reliability of the reactive strength index and time to stabilization during depth jumps. The Journal of Strength \& Conditioning Research, 2008, 22(5): 16771682.

26. Demirkan E. Serbest ve Grekoromen Yildiz Milli Takimlarina Seçilen Ve Seçilemeyen Güreşçilerin Bazi Özelliklerinin Karşilaştirilmasi. Sağlik Bilimleri Enstitüsü, Beden Eğitimi ve Spor Anabilim Dalı. Doktora tezi, Ankara: Ankara Üniversitesi, 2012.

27. Aydos L, Taş M, Akyüz M, Uzun A. Genç Elit Güreşçilerde Kuvvetle Bazi Antropometrik Paremetrelerin İlişkisinin İncelenmesi. Beden Eğitimi ve Spor Bilimleri Dergisi, 2009, 11(4): 1-10.

28. Güven Ö. Türklerde Spor Kültürü, 2. Bask1. Ankara, Alp Ofset, 1999.

29. Yıldız M. Türkiye’ye Cumhuriyet Döneminde Beden Eğitimi ve Spor Alanında Gelen Yabancı Uzmanların İstihdamı, Çalışmaları ve Etkileri (1923-1973). Eğitim Bilimleri Enstitüsü, Beden Eğitimi ve Spor Öğretmenliği Anabilim Dalı. Yayımlanmamış Doktora tezi, Ankara: Gazi Üniversitesi, 2020.

30. Güven Ö, Yıldız M. Turkey In 1968 Mexıco City Olympıcs. Sözel Bildiri. Firat University, Elazig, Turkey: The 10th International Conference In Physical Education, Sports And Physical Therapy, November 18-20; 2016. 
31. Yıldız M, Güven Ö. Turkey In 1968 Mexıco City Olympıc Games. European Journal of Physical Education and Sport Science, 2018: 54-63.

32. Yıldız M, Güven Ö, Karaca Y. 1960 Roma Olimpiyat Oyunları’nda Türkiye. Sözel Bildiri. Antalya, Türkiye: 18. Uluslararası Spor Bilimleri Kongresi 07 - 09 Kasim 2020.

33. Yıldız M, Güven Ö, Güven EU. 1956 İstanbul Dünya Kupası Güreş Müsabakalarında Türkiye. Türkiye Spor Bilimleri Dergisi, 2020, 4(2): 124-132.

34. Yıldız M, Güven Ö, Şanlı G. 1966 Toledo Dünya Güreş Şampiyonası'nda Türkiye. Kilis 7 Aralı Üniversitesi Beden Eğitimi ve Spor Bilimleri Dergisi, 2021, 4(2): 124-140.

35. Güven Ö. Türk Güreş Ekolü. Türk Güreş Vakfı Dergisi, 2015, 1: 22-27.

36. Bompa TO. Periodization: Theory and Methodology of Training . Çeviri: Bağırgan T. Dönemleme: Antrenman Kuramı ve Yöntemi, 5. Baskı. Ankara, Spor Yayınevi ve Kitabevi, 2015: 329-430.

37. Bompa TO. Theory and methodology of training. Çeviri: Keskin I, Tuner AB, Küçükgöz H, Bagırgan T. Dönemleme: Antrenman Kuramı ve Yöntemi, 3. Baskı. Ankara, Spor Yayınevi ve Kitapevi, 2007: 321-390.

38. Tamer K. Sporda Fiziksel-Fizyolojik Performansın Ölçülmesi ve Değerlendirilmesi, 2. Baskı. Ankara, Bağırgan Yayımevi, 2000: 32-154.

39. Günay M, Tamer K, Cicioğlu İ. Spor Fizyolojisi ve Performans Ölçümü, 3. Baskı. Ankara, İlksan Matbaası Ltd. Şti., 2013: 103-557.

40. Günay M. Egzersiz Fizyolojisi, 1. Baskı. Ankara, Bağırgan Yayımevi, 1998: 37-102.

41. Gelir E, Koz M. Fizyoloji Ders Kitabı, 4. Baskı. Ankara, Hazar Matbaac1lik, 2013: 211-215.

42. Tart121. Portable Stadiometer. https://tarti.com/portable-stadiometer-urun52.html. 13.07.2019.

43. Tartı21. Tanıta Bc 418 Vücut Analiz. http://tartimedikal.com/tanita-bc-418-vucut-analiz.html. 13.07.2019.

44. Healy R, Kenny IC, Harrison AJ. Assessing Reactive Strength Measures in Jumping and Hopping Using the Optojump (TM) System. J Hum Kinet, 2016, 54(1): 23-32.

45. Lehnert M, Hůlka K, De Ste Croix MB, Horutová K. Acute effect of basketball-specific exercise on lower limb injury risk mechanis$\mathrm{ms}$ in male basketball players U16 and U18. Research and Investigations in Sports Medicine, 2018, 2(3): 1-6. 
46. Markwick WJ, Bird SP, Tufano JJ, Seitz LB, Haff GG. The intraday reliability of the reactive strength index calculated from a drop jump in professional men's basketball. Int J Sport Physiol Perform, 2015, 10(4): 482-488.

47. Flanagan EP, Comyns TM. The use of contact time and the reactive strength index to optimize fast stretch-shortening cycle training. Strength \& Conditioning Journal, 2008, 30(5): 32-38.

48. Lazaridis SN, Bassa EI, Patikas D, Hatzikotoulas K, Lazaridis FK, Kotzamanidis CM. Biomechanical comparison in different jumping tasks between untrained boys and men. Pediatric Exercise Science, 2013, 25(1): 101-113.

49. Santos EJ, Janeira MA. The effects of resistance training on explosive strength indicators in adolescent basketball players. The Journal of Strength \& Conditioning Research, 2012, 26(10): 2641-2647.

50. Globususa. Drop Jump. http://www.globususa.com/jumping-assessment. 13.07.2019.

51. Aslan CS, Büyükdere C, Köklü Y, Özkan A, Özdemir FNŞ. Elit altı sporcularda vücut kompozisyonu, anaerobik performans ve sırt kuvveti arasındaki ilişkinin belirlenmesi. Uluslararası İnsan Bilimleri Dergisi, 2011, 8(1): 1612-1628.

52. Bayraktar I. 13-17 Yaş Grubu Atlet ve Güreşçilerin Bazı Fiziksel ve Fizyolojik Parametrelerinin Normatif Çalışması. Sağlık Bilimleri Enstitüsü, Beden Eğitimi ve Spor Anabilim Dalı. tezi, Ankara: Gazi Üniversitesi, 2010.

53. Microgate. Optojump Next. http://www.optojump.com/Applications.aspx. . 13.07.2019.

54. Elsa. Baseline Back Leg Chest Dynamometer. http://www.elsa. web.tr/tr/urun/olcme-degerlendirme/hidrolik-el-dinamometresi/ fabrication-enterprises-baseline-back-leg-chest-dynamometer. 13.07.2019.

55. Elsa. Baseline HD Hydraulic Hand Dynamometer 200 LB HD. http://www.elsa.web.tr/tr/urun/olcme-degerlendirme/hidrolik-el-dinamometresi/fabrication-enterprises-baseline-hd-hydraulic-hand-dynamometer-200-lb-hd. 13.07.2019.

56. Alpar R. Spor, Sağlık ve Eğitim Bilimlerinden Örneklerle Uygulamalı İstatistik Ve Geçerlik-Güvenilirlik, 4. Baskı. Ankara, Detay Yayıncilık, 2016.

57. Şahin A. Grekoromen Ve Serbest Stil Güreş Yapan Sporcuların Kendileriyle Konuşma Düzeylerinin İncelenmesi. Kilis 7 Aralı Üniversitesi Beden Eğitimi ve Spor Bilimleri Dergisi, 2017, 1(1): 60-64. 
58. Kaçmaz İ. Groko-romen Güreş Tekniklerinin Serbest Güreş Müsabakalarında Başarıya Etkisi. Sağlık Bilimleri Enstitüsü, Beden Eğitimi ve Spor Anabilim Dalı. Yüksek Lisans tezi, Ankara: Gazi Üniversitesi, 1992.

59. Akyüz M. Elit Güreşçilerde Hizli Kilo Kaybinin Fiziksel Fizyolojik ve Biyokimyasal Parametrelere Etkisi. Sağlık Bilimleri Enstitüsü, Beden Eğitimi ve Spor Anabilim Dalı. Doktora tezi, Ankara: Gazi Üniversitesi, 2009.

60. Alpay CB, Hazar S, Gökdemir K, Güzel NA, Gönenç A, Simsek $B$. The effects of thyme tea supplement on free radicals formation and antioxidant system of elite wrestlers. Pakistan Journal of Nutrition, 2013, 12(5): 433-440.

61. Mirzaei B, Nezhad AA. A skill profile of elite Iranian Greco-roman wrestlers. World J Sport Sci, 2008, 1(1): 8-11.

62. Barbas I, Fatouros IG, Douroudos II, Chatzinikolaou A, Michailidis Y, Draganidis D, Jamurtas AZ, Nikolaidis MG, Parotsidis C, Theodorou AA. Physiological and performance adaptations of elite Greco-Roman wrestlers during a one-day tournament. European journal of applied physiology, 2011, 111(7): 1421-1436.

63. Karnincic H, Tocilj Z, Uljevic O, Erceg M. Lactate profile during Greco-Roman wrestling matchx. Journal of sports science \& medicine, 2009, 8(3): 17-19.

64. Ayar M. Elit Grekoromen Güreşçilerde Müsabaka Öncesi Dönemde Uygulanan Ağırlık Kaybına Yönelik Beslenme Programının, Vücut Kompozisyonu, Kuvvet Ve Duygudurum Profiline Etkisi. Sağlık Bilimleri Enstitüsü, Beden eğitimi ve Spor Anabilim Dalı. Yüksek Lisans tezi, İstanbul: Marmara Üniversitesi, 2018.

65. Işı Ö. Elit Güreçilerde Dehidrasyonun İskelet Kası Hasarı ve İnflamasyon Üzerine Etkisi. Sağlık Bilimleri Enstitüsü, Beden Eğitimi ve Spor Anabilim Dalı. Doktora tezi, Ankara: Gazi Üniversitesi 2015.

66. Kaya K. 12 Haftalık Çabuk Kuvvet Antrenman Programının Güreşçilerin Dinamik Denge, Bacak Kuvveti, Relatif Güç, Sürat ve Vücut Kompozisyonuna Etkisinin İncelenmesi. Sağlık Bilimleri Enstitüsü, Beden Eğitimi ve Spor Anabilim Dalı. Yüksek Lisans tezi, Afyonkarahisar: Afyon Kocatepe Üniversitesi, 2018.

67. Beckham GK, Suchomel TJ, Bailey CA, Sole CJ, Grazer JL, editors. The relationship of the reactive strength index-modified and measures of force development in the isometric mid-thigh pull. ISBS-Conference Proceedings Archive; 2013. 
68. Zorba E, Özkan A, Akyüz M, Harmancı H, Taş M, Şenel Ö. Güreşçilerde bacak hacmi, bacak kütlesi, anaerobik performans ve bacak kuvveti arasındaki ilişki. Uluslararası İnsan Bilimleri Dergisi, 2010, 7(1): 83-96. 